\title{
LOS LIBROS DE TRAJES EN EL SIGLO XVI: PERSPECTIVAS CRÍTICAS PARA SU INVESTIGACIÓN
}

\author{
Rebeca García Haro* \\ UNIVERSIDAD DE GRANADA
}

\begin{abstract}
RESUMEN
Los libros de trajes, como una tipología de fuente que tiene su primer desarrollo durante el siglo XVI, aportan un espacio de representación sociocultural de dicho periodo, al igual que otros recursos documentales de carácter textual y visual, como las cartografías o la literatura de viajes. Desde un marco teórico feminista y poscolonial, pueden aportarnos datos relevantes sobre dichas figuraciones desde los discursos de poder en los comienzos de la llamada modernidad, y en especial la construcción de la otredad, tanto corporal como territorial. Estudiado desde su propia materialidad, el libro de trajes nos habla de los procesos que tienen lugar alrededor de su aparición con el desarrollo de la imprenta, hasta la actualidad, que los sitúa en los grandes centros de manifestación de la cultura principal, las bibliotecas.
\end{abstract}

PALABRAS CLAVE: Renacimiento, feminismo, poscolonialidad, espacios, representaciones

\footnotetext{
*rebecagarciaharo@gmail.com
} 
ISSN: 0212-5099

E-ISSN: 2695-7809

DOI: 10.24310/BAETICA.2019.v0i39.6776

\title{
RENAISSANCE COSTUME BOOKS: NEW APPROACHES ON RESEARCH
}

\author{
Rebeca García Haro* \\ UNIVERSIDAD DE GRANADA
}

\begin{abstract}
Renaissance costume books establish a space of socio-cultural representation as well as other visual and textual sources such as cartography or travel literature. From a feminist and postcolonial perspective they can provide us relevant information about power discourses, especially about the representation of corporal and territorial alterity. Studied from its own materiality, the book of costumes tells us about the processes that take place around its appearance with the development of the printing press, until today, which places them in the great centers of manifestation of the main culture, libraries
\end{abstract}

KEYWORDS: Renaissance, feminism, postcoloniality, spaces, representation.

Enviado: 4/12/2019

Aceptado: 18/05/2020

*rebecagarciaharo@gmail.com 


\section{INTRODUCCIÓN}

Las imágenes componen sin lugar a dudas, una fuente de información excepcional para el estudio del pasado, particularmente, desde que la historia social y cultural, les diesen su debida importancia, partiendo de un análisis crítico e interdisciplinar ${ }^{1}$. Entendidas entonces como textos visuales, las imágenes muestran formas concretas de mirar y conocer el mundo, funcionando como verdaderos $\operatorname{archivos}^{2}$ que reflejan las estrategias del saber desde culturas concretas, y que a través de representaciones propias y ajenas, nos hablan sobre "cuerpos que cuentan y cuerpos que son contados"

Así, el estudio de los textos visuales durante el período que ocupa el siglo XVI en Europa, conocido como Tardorrenacimiento o Renacimiento tardío, puede proporcionarnos un campo de estudio desde el cual aprehender la manera en la que se trazan los discursos del poder, así como la creación de la diferencia desde la percepción europea del "yo" frente al "otro", en un tiempo caracterizado por el enfrentamiento religioso, territorial y el gran paradigma de la colonización americana. Ideas que vendrán auspiciadas por el uso y proliferación de la imprenta y el libro.

Reflexión esta, que no pasa solo sobre aquellas fuentes consideradas "artísticas" o "pictóricas", sino también sobre aquellos dibujos, estampas o grabados que ilustran y componen fuentes tan características como los mapas, las cartografías, las crónicas de viajes, y muy en especial, los libros de trajes. Imágenes que han sido portadoras de una genealogía casi atemporal, dada su gran difusión y uso hasta la actualidad.

Para dibujar entonces un marco hipotético, partimos de la idea de que si bien el libro de trajes ha sido ampliamente utilizado para la difusión de sus imágenes, que han ilustrado estudios y trabajos, dicha fuente no se ha estudiado en profundidad desde su materialidad al plano simbólico, pasando por las redes de poder que lo intersectan.

En el presente trabajo, el libro de trajes será entendido como un espacio creador de otros espacios, tanto desde el plano material como simbólico. Como una fuente con significado propio cargada de otros significados

1. Léase a modo general P. Burke (2005). Desde un pensamiento más interdisciplinar feminista, de género y poscolonial, véanse los trabajos de G. Rose (2001), A. Jones (2003) y M. Sturken \& L. Cartgright (2009).

2. Idea tomada de las reflexiones de Michel Foucault en torno al archivo en M. Foucault (1979).

3. Planteamiento desarrollado en R. García Haro (2018). 
concretos, resultantes de un contexto específico. Unos libros que partiendo de los diversos estudios hasta la fecha, tendrían su primer desarrollo en Europa hacia la segunda mitad del siglo XVI, desde tres áreas geográficas distintas, siendo estas la francesa, la germana y la italiana ${ }^{4}$.

Entonces, tras una definición amplia sobre lo que entendemos como libro de trajes, el presente texto expone un estado de la cuestión en la actualidad al que se sumarán las necesidades teórico-metodológicas que nos permitan abarcar al libro de trajes en su conjunto. Posicionamiento crítico que partirá desde los estudios culturales, en una clara perspectiva feminista y poscolonial, que va a permitir incidir en el análisis de las identidades e intersecciones que surgen en torno al libro de trajes, desde los conceptos de género, estatus y raza.

Finalmente, esta tesis será ilustrada con el estudio de la creación, circulación y difusión del libro en particular y del libro de trajes en particular, a través de la investigación del fondo antiguo de la Biblioteca Nacional de España. La elección de dicho fondo se debe a la importante colección de libros de trajes y otras fuentes relacionadas del periodo que en dicho archivo bibliotecario podemos encontrar, lo que permitirá no solo delimitar el análisis de nuestra hipótesis inicial, sino establecer una genealogía documental del libro de trajes en esta biblioteca. En concreto, los libros protagonistas de este estudio serán aquellos de autoría italiana, que debido a su mayor presencia, nos harán entender mejor las redes de circulación del saber en la Europa del Mediterráneo durante el periodo moderno.

\section{ELLIBRO DE TRAJES: PROPUESTAS TEÓRICO-METODOLÓGICAS PARA SU ESTUDIO}

Para empezar por una idea general sobre lo que es un libro de trajes y su propia estructuración, contamos por un lado con la definición que nos proporciona la historiadora del arte Ulrike Ilg, en "The Cultural Significance

4. No existe "regla" establecida sobre un modelo específico de "libro de trajes" desde el cual se deriven los demás, ni tampoco un esquema claro sobre las diversas tipologías de libros de trajes que encontramos en Europa durante el siglo XVI, más allá de la clasificación que se expone en este trabajo, partiendo del estado actual de la cuestión. Aun así, es cierto que dependiendo de cada área geográfica o periodo de creación, el libro de trajes sufre modificaciones técnicas y formales, pero ello no los excluye de la definición general que presentaremos en el epígrafe siguiente. Este es un debate que, aunque no se plantea en el presente artículo, existe y permanece en abierto para el cual pueden consultarse los trabajos de M. BirRiel Salcedo (2013) y (2019) y R. Ruíz Álvarez (2011) y (2013). 
of Costume Books in Sixtheenth-Century Europe" (2004), que los define como "aquellos libros consistentes en una serie de xilografías o calcografías que representan a personas autóctonas de todas partes del mundo"5.

Por otra parte, Margarita M. Birriel Salcedo, en "Clasificando el mundo. Los libros de trajes en la Europa del siglo XVI" (2013), los describe como "aquel libro ilustrado cuyo objetivo es la recopilación explícita y más o menos sistemática, de dibujos, grabados o estampas, sobre diversas formas de la indumentaria humana". Una fuente, que según los datos arrojados por la citada autora, verá su fase de mayor desarrollo durante el siglo XVI, coincidiendo con una serie de cambios políticos, sociales y económicos en el contexto europeo, del cual estos libros serán consecuencia directa.

De este modo, a través de la presentación de una serie de imágenes antropomorfas, generalmente sobre fondo plano, y acompañadas por una breve definición -en la mayor parte de los casos- los libros de trajes van a mostrar una visión específica del mundo desde las líneas de creación y difusión del conocimiento de la Europa tardorrenacentista.

Imágenes en las cuales, el vestido como marcador sociocultural será el principal protagonista, pero no el único. Serán otros los indicadores que funcionarán haciéndose parte de la propia indumentaria, como el peinado, los objetos decorativos o los elementos suntuarios, así como la propia escenificación del cuerpo. Es decir, a través de esta puesta en escena, el cuerpo funciona como un texto visual codificado que, en cada contexto, nos muestra una escenografía de modos del $\operatorname{ser}^{7}$.

Un texto visual que, a través del breve texto que aparece al pie de la imagen, nos ofrece información sobre el género, el estatus y el lugar de procedencia de la persona representada, con el añadido de la edad en las representaciones femeninas, biológicamente ligada durante la Edad Moderna a la fertilidad ${ }^{8}$, así como su estado civil ${ }^{9}$. Datos que ponen en relieve cuestiones que debían ser cruciales en el marco representativo en el cual nos movemos, y en consecuencia, puntos clave para hablar de diferenciación social, cultural y sexual durante el siglo XVI.

Unas estrategias que nos acercan a la estructuración de las fuerzas de representación e intersecciones presentes en los libros de trajes, desde un

5. U. ILG (2004), 29.

6. M. Birriel Salcedo (2013), 261.

7. Ibidem, 262.

8. M. Wiesner-Hanks (2013), 50-85.

9. U. ILG (2004), 40. 
poder que se nos presenta como explícitamente patriarcal, eurocéntrico y colonial, expresado a través del "yo masculino" representativo del canon de estructuración política, frente a la otredad femenina, siempre como contraparte, así como el "yo europeo" normativo frente a la otredad exterior.

Figuraciones corporales que se crean en torno a una supuesta neutralidad de representación europea, pero que va a privilegiar a unos cuerpos sobre otros, bajo unas normas y códigos morales relativos a los parámetros culturales del Antiguo Régimen.

De manera concreta, coincidiendo con el denominado Renacimiento científico $^{10}$, cuyo mayor exponente será el estudio de la otredad, los libros de trajes pertenecerán por tanto al impulso cartográfico que recorrerá Europa durante todo el siglo XVI, y que se hará patente a través de la cartografía y la literatura de viajes.

Es por tanto, que estudiar los libros de trajes desde su complejidad, será lo que nos acerque a resultados más amplios sobre las formas del ser y del conocer(se) durante el siglo XVI europeo, y sobre los diferentes discursos del poder desde una fuente precisa que trata de presentar una visión "global" del mundo conocido, a través de cartografías corporales.

Y dicha complejidad puede ser precisada a través del análisis de sus diferentes espacios. En primer lugar, el propio contexto que dará lugar al libro de trajes como espacio y plataforma de difusión, que pasa por el desarrollo de la imprenta, el formato librario y por supuesto, de un mercado del libro. A su vez, el propio contexto en el que posteriormente se han conservado estas fuentes. En segundo lugar, desde el sentido territorial que proyectan los libros de trajes a través de la propia construcción de fronteras político-religiosas, a través de la disposición de las distintas imágenes y su lectura simbólica e iconográfica. Y, en tercer lugar, el cuerpo como primer espacio, desde el cual se dibujan barreras ontológicas en relación a la identidad, desde cuestiones como el género, el estatus o la raza.

\section{DESDE LOS ESTUDIOS CULTURALES A LA TEORÍA FEMINISTA Y POSCOLONIAL: UN ESTADO ACTUAL DE LA CUESTIÓN}

En los últimos años, han sido las visiones de distintas autoras y autores a través de los denominados estudios culturales, las que han sentado las bases para el estudio meticuloso del libro de trajes, gracias a que este complejo marco analítico, ha supuesto una sólida y plural línea de trabajo,

10. P. Burke (2000), 93-17. 
desde la interdisciplinariedad en la que confluyen visiones desde la historia, la geografía la filosofía, la antropología, la sociología, la lingüística, la crítica visual, o la literatura comparada ${ }^{11}$.

En "Un genere ethnographique profane au XVIe siècle, les livres d'habits" (1984), Daniel Defert será el primer autor que no habla del libro de trajes como libros de indumentaria, sino como lo que podrían ser una especie de primigenios estudios etnográficos del siglo XVI, abriendo el camino a un estudio crítico desde la complejidad que dicha fuente conlleva. Además, contribuye al estudio de los mismos aportando en su análisis el concepto habitus del sociólogo Pierre Bourdieu ${ }^{12}$.

Como monografía, Jeannine Guérin Dalle Mese en L'occhio di Cesare Vecellio. Abiti e costumi esotici nel'500 (1998), realiza un estudio preciso sobre los cambios que sufre el libro de trajes a través de ejemplos de autoría italiana, haciendo hincapié sobre la importancia en su vinculación con la cartografía y la literatura de viajes, fuentes de las cuales se nutre, así como de la repetición que se lleva a cabo en el uso de las mismas, y de las distintas imágenes entre los diferentes autores ${ }^{13}$.

En el ya citado artículo de Ulrike Ilg, la autora hace una lectura del libro de trajes desde su sentido de territorialidad, en el cual, a través de las distintas imágenes, la diferencia como eje vertebrador de las distintas representaciones, hace de contingente como fronteras físico-espaciales ${ }^{14}$.

Margaret F. Rosenthal y Ann Rosalind Jones, en su introducción para la versión facsímil en inglés del libro de trajes de Cesare Vecellio, The Clothing of the Renaissance World (2008), llevan a cabo un análisis realmente interesante sobre la propia realidad del autor y la importancia del vestido como marcador social en la cotidianeidad de la Venecia de finales del siglo XVI, sumado a una reseña sobre los procesos de producción del libro así como del público a quien va dirigida la información contenida en el libro de trajes de Cesare Vecellio. Pero especial importancia tiene su referencia al Nuevo Mundo y a la construcción de imaginarios que a partir de dicha época se van a llevar a cabo desde Europa. Unos imaginarios que se fundan a partir de concepciones eurocéntricas, y basados en las informaciones suministradas por la literatura de viajes y las cartografías ${ }^{15}$.

11. C. Barker \& E. A. Jane (2016); C. Tilley (2006).

12. D. Defert (1984).

13. J. Guérin Dalle Mese, (1998).

14. U. ILG (2004).

15. M. F. Rosenthal \& A. R. Jones (2008), 8-48. 
Más que interesante es el libro de Ulinka Rublack, Dressing Up. Cultural Identity in Renaissance Europe (2010), como obra de referencia, que nos ofrece una especie de plantilla de seguimiento, en la que relaciona la representación corporal con la representación territorial, y la estructuración de las diferencias tanto al interno como al externo de Europa ${ }^{16}$.

Margarita M. Birriel Salcedo, en el ya citado artículo "Clasificando el mundo. Los libros de trajes en la Europa del siglo XVI" (2013), da una visión general sobre el significado del libro de trajes entendido como artefacto de la cultura material, en relación con la importancia que tiene el desarrollo y difusión tanto de la imprenta como del libro en Europa, durante un tiempo en el cual, la creación de "una identidad otra" resulta esencial para la construcción de una identidad propia, desde las diferencias de género y estatus social, pasando por las religiosas hasta la raza. Toda una serie de intersecciones que en definitiva pretenden ordenar el yo frente a otro u otra, un nosotros frente a unos otros ${ }^{17}$.

Y finalmente, Eugenia Paulicelli, en Writing Fashion in Early Modern Italy (2016), nos ofrece un análisis de los libros de trajes como textos visuales desde la literatura comparada, llevando a cabo una lectura del cuerpo y sus significados en los libros de trajes en Italia, a través de términos como virtud, ciudadanía o civilización ${ }^{18}$.

De modo que, desde la multiplicidad de análisis que nos ofrecen los estudios culturales, podemos desvelar toda una serie de códigos de producción y representación en el libro de trajes, sumado a un posicionamiento feminista y poscolonial, haciendo uso de las categorías de género, el estatus o la raza. Dichas categorías evidenciarán la diferencia como eje de cohesión desde la visión específica de cómo se reconoce a mujeres y hombres a través de sus cuerpos y como sujetos endógenos u alógenos a la normatividad eurocéntrica, patriarcal, heterosexual y colonial.

La necesidad de introducir la teoría feminista pasa por el estudio profundizado del cuerpo y la sexualidad tanto femenina como masculina que se proyecta en los libros de trajes, los roles de género, hábitos y comportamientos, que aparecen divididos en esferas separadas, desde una visión androcéntrica y heteronormativa.

Para ello, se puede trabajar con autoras como Adriana Cavarero ${ }^{19}$, Hélène

16. U. RUBLACK, (2010).

17. M. Birriel Salcedo (2013).

18. E. Paulicelli (2016).

19. A. Cavarero (1998). 
Cixous $^{20}$ o Julia Kristeva desde la literatura comparada, en una lectura de la diferencia a través de las representaciones del cuerpo femenino y masculino. Con las filósofas Judith Butler ${ }^{21}$ o Donna Haraway ${ }^{22}$, para entender el género como performativo, como una tecnología que es culturalmente construida y que determina los cuerpos dependiendo de su sexuación. Con la geógrafa Linda $\mathrm{McDowe}^{23}$, para entender el género como un elemento fluido que cambia según el lugar y cómo a su vez, el género crea otros espacios de diferenciación, desde el cuerpo hasta la visión espacial en su más amplio sentido. Y por último, destacar también a Marita Sturken y Lisa Cartwright ${ }^{24}$, expertas en crítica visual, que se centran en un análisis sobre la creación, el uso y la lectura de las imágenes y la representación desde una perspectiva histórica, situada y de género, especialmente centradas en cómo se establecen los cánones de representación.

Por otro lado, la importancia de incluir la teoría poscolonial para estudiar la representación de la otredad tanto dentro como fuera de las fronteras que se edifican en torno a la construcción de una identidad y una forma de ser europeas.

Entre muchos otros, podemos citar a Edward $\mathrm{Said}^{25}$ y sus estudios sobre el orientalismo, a Frantz Fanon ${ }^{26}$ y los estudios sobre la negritud o "identidad negra", a Gayatri Spivak ${ }^{27}$ y los estudios de subalternidad, en especial sobre la representación de las mujeres como subalternas del sujeto subalterno en una doble discriminación y violencia epistémica, Paul Gilroy $^{28}$ y sus observaciones sobre los movimientos en el Atlántico y las formas de ejercer el poder en este espacio de trasvase cultural, y Homi K. Bhabha $^{29}$ y sus análisis sobre el poder que ejerce la colonialidad sobre el sujeto colonizado, que tiende a darnos una imagen fija y estereotipada en su representación.

20. H. Cixous (1995)

21. J. ButLer (2002).

22. D. Haraway (2016).

23. L. MCDowell (2000).

24. M. Sturken \& L. Cartwright (2009).

25. E. SAID (2008).

26. Reflexiones sobre Franz Fanon y su obra Black Skin, White Masks, en H.K. Bнabнa (2002), 61-89.

27. G.C. SPIVAK (1998).

28. P. Gilroy (2014).

29. H.K. Внавна (2002).

(C) Baetica. Estudios Historia Moderna y Contemporánea, 40, 2020, 13-34. Facultad de Filosofia y Letras, Universidad de Málaga. Departamento de Historia Moderna y Contemporánea 
Autores como Enrique Dussel ${ }^{30}$, Walter Mignolo $^{31}$ o Aníbal Quijano ${ }^{32}$, deben ser citados con explícita importancia, pues gracias a ellos se reconoce el alcance del concepto "modernidad"33 a partir del siglo XVI. Un concepto que se interpreta como la centralización del discurso desde el poder, la ciencia y la moralidad en Europa, y su papel clave sobre "el paradigma americano", donde se ejerce una colonización a través de tres vertientes, del poder, del saber y del $\operatorname{ser}^{34}$.

\section{HABLAR DE ESPACIO(s): CONTEXTO(s)}

Un primer punto clave para el estudio del libro de trajes es abarcándolo desde su propia materialidad, partiendo del análisis del contexto en el cual este se produce y de qué manera, hasta el lugar donde podemos localizarlo en la actualidad. En "Espacio y género en la Edad Moderna. Retos, problemas y logros de la investigación" (2016), Margarita M. Birriel Salcedo expone que "el espacio/los espacios surgen de relaciones de poder, relaciones que rigen normas, normas que definen exclusión/pertenencia; que hablan de discursos, pero también de prácticas ${ }^{35}$ ". De modo que siguiendo esta afirmación, hemos de entender el propio contexto del quinientos en general, y de la producción de libro de trajes en particular, como un espacio fluido, no como una disposición de acciones o actividades binarias, sino desde las distintas intersecciones que este proyecta.

A partir del siglo XVI, la difusión de la imprenta y del libro, verá un desarrollo clave para la construcción del aparato ideológico en el Antiguo Régimen. Si por un lado, la imprenta va a concentrarse en ciertos focos específicos, por otro, el propio mercado librario, con presencia en las ferias más importantes de Europa, estará en manos de impresores y editores (quienes suelen ser la misma persona), que van a imprimir aquellas obras que les generen rentabilidad y cierto grado de seguridad. Y esto lo harán a través de una relación en doble sentido en la cual concuerdan con las instituciones tanto públicas como religiosas aquellas obras que desean ser leídas. Además, será de estas mismas instituciones de donde salgan los autores de dichas impresiones ${ }^{36}$.

30. E. Dussel (2000).

31. W. Mignolo (2007).

32. A. Quijano (2007).

33. E. Dussel (2000), 27.

34. A. QuiJano (2007), 118-120.

35. M. Birriel Salcedo (2016), 93.

36. A. Pettegree (2010), 65-80. 
La producción del libro de trajes se inserta por tanto en el marco de estas relaciones, y a su vez, dentro del ya citado Renacimiento científico, cuyo punto de referencia será la otredad como objeto de estudio. Un marco en el cual se imprimen obras que, al igual que los libros de trajes, hacen patente un mapeo de la otredad, nutriéndose unas de otras. Obras como los manuales científicos, de botánica, las cartografías o la literatura de viajes, que hacen visible una relación desigual entre quienes tienen la potestad de representar y quienes son representadas/os.

El siguiente paso por tanto es conocer el lugar donde actualmente encontramos estas fuentes, que en este caso es el fondo antiguo de las bibliotecas, bien sean públicas o privadas. Partiendo pues de las pinceladas que ya nos daba Arlette Farge en Le goût de l'archive (1989) ${ }^{37}$ y sus reflexiones sobre el archivo y la importancia de estudiar sus silencios y ausencias cambiando sus preguntas, junto a los instrumentos que nos proporciona Michel Foucault en su Arqueología del saber $(1969)^{38}$, podemos interpretar el fondo antiguo como un archivo. A su vez, estudiar el libro de trajes como un archivo, como un objeto material que nos refiere toda una serie de información ${ }^{39}$. Y finalmente, reconocer cómo ambos han sido producidos en torno a lo que podríamos interpretar como una genealogía del saber ${ }^{40}$, que en el tiempo ha permanecido como expresión cultural de la Europa del siglo XVI, al interno de unas relaciones de poder entre la producción científica y la otredad como objeto de estudio, en la que unos cuerpos tendrán el derecho de representar(se) y otros serán representados, dando lugar a un conjunto de imágenes fijas y estereotipadas que harán patente la diferencia corporal como línea de coherencia.

\subsection{Un caso de estudio: una genealogía del saber en el fondo antiguo de la Biblioteca Nacional de España}

Tras un sondeo sobre el fondo antiguo de la Biblioteca Nacional de España, y contrastando los distintos estudios vinculados a los libros de trajes, se pueden contabilizar una obra perteneciente al área francesa, el Habitus variarum orbis gentium (1581) de Jean Jacques Boisard, de la

37. A. FARge (2004), 32-40.

38. J. W. Márquez Estrada (2014).

39. Esta idea habría sido imposible de desarrollar sin los trabajos del historiador R. CHARTIER (2000a) y (2000b).

40. J. W. Márquez Estrada (2014). 
cual hay dos copias. Tres obras del área germana, el Omnium fere gentium, nostraeque aetatis nationum habitus et effigies (1572), de Joanes Ballerus, el Habitus praecipuorum populorum (1577) de Jost Amman, y el Omnium pene Europae, Asiae, Aphricae, atque Americae gentium habitus (1581) de Abraham Brüyn. Y por último, cinco del área italiana, el Omnium fere Gentium nostrae aetatis habitus (1563) de Ferdinando Bertelli, el De $i$ veri ritratti degli'habiti di tutte le parti del mondo. Intagliati in rame pero opra di Bartolomeo Grassi (1585) de Bartolomeo Grassi, el Diversarum nationum habitus centum $(1589,1591,1596)$ de Pietro Bertelli, el Habiti antichi et moderni di tutto el mondo di Cesare Vecellio di nuovo acresciuti di molte figure (1598) de Cesare Vecellio y, por último, el Habiti delle donne venetiane intagliate in rame (1614) de Giacomo Franco ${ }^{41}$.

Esto permite observar una serie de "patrones" que muestran, en primer lugar, un período de larga duración desde la aparición del libro de trajes hacia la mitad del siglo XVI, y hasta la primera década del XVII, en el que este va a ver una serie de cambios en consecuencia a la mejora técnica del libro. En segundo lugar, la presencia de tres focos de producción, que van a ser el área francesa, el área germana, y el área italiana. Y en tercer lugar, que en el fondo de la Biblioteca Nacional encontramos una preferencia por las obras de impresión y autoría italiana, debido a que serán Venecia y Roma las ciudades que controlen el mercado de lo impreso en la Europa del Mediterráneo ${ }^{42}$.

Tras estos resultados, trabajar con las cinco obras de autoría italiana llevando a cabo un estudio minucioso sobre cada una de ellas, nos permite por un lado establecer la correlación con la temporalidad y la mejora técnica en el libro de trajes, y por otro, analizar las imágenes entre unas y otras, las copias y repetición temática.

Como primera obra, en 1563, tenemos la de Ferdinando Bertelli, Omnium fere gentium nostrae aetatis habitus, que como apunta Jeannine Guérin Dalle Mese, sería copia directa del de Enea Vico ${ }^{43}$. El fondo antiguo de la Biblioteca Nacional de España, cuenta con dos volúmenes de este libro de trajes, editado en la ciudad de Venecia. Un primero, con portada grabada original, que muestra como año de edición 1563, y un segundo, que cuenta con una portada con grabado añadida a posteriori, en la que versa el título

41. Resultados visibles a partir del estudio in situ del fondo antiguo de la Biblioteca Nacional de España.

42. A. Pettegree (2010), 249-258.

43. J. Guérin Dalle Mese (1998), 12-14. 
original y como año de edición 1569. Los grabados que componen el libro, de tipo xilográfico ${ }^{44}$ y en tinta simple sin colorear, sitúan las imágenes antropomorfas de forma sencilla e individualmente sobre un fondo plano, y con un pequeño cartel en un extremo del grabado en el cual se indica la información básica de la persona representada en la imagen.

\section{Imagen 1}

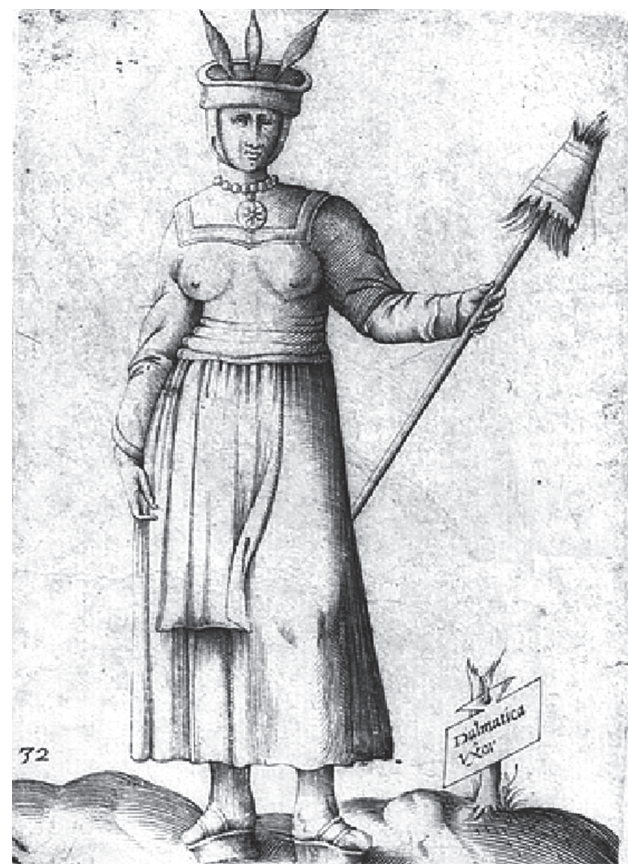

F. Bertelli, Omnium fere gentium nostrae aetatis habitus, 1563.

Biblioteca Digital Hispánica (BDH).

En segundo lugar contamos con un ejemplar muy bien conservado del libro de trajes de Bartolomeo Grassi, De i veri ritratti degli'habiti di tutte le parti del mondo. Intagliati in rame pero opra di Bartolomeo Grassi, que data de 1585 y editado en Roma. Una obra de maravillosos grabados calcográficos, de gran belleza y cuidado en cada una de sus imágenes. Las

44. Para cuestiones sobre grabado véase la obra de Antonio Moreno Garrido (1979). Para unas nociones básicas sobre las diferencias entre el grabado xilográfico (en madera) y calcográfico (en metal) y sus diferencias técnicas y estilísticas puede consultarse el mismo trabajo. 
personas que se representan se sitúan de a tres o a cuatro en cada página y cuentan con una breve definición a los pies o a la cabeza de cada una. Pero además el libro de Bartolomeo Grassi es precisamente interesante por la disposición misma de sus imágenes, pues muestran grupos de personas que aparecen relacionándose entre si y que en ocasiones, dependiendo de su posicionamiento, manifiestan verdaderas jerarquías sociales.

\section{Imagen 2}

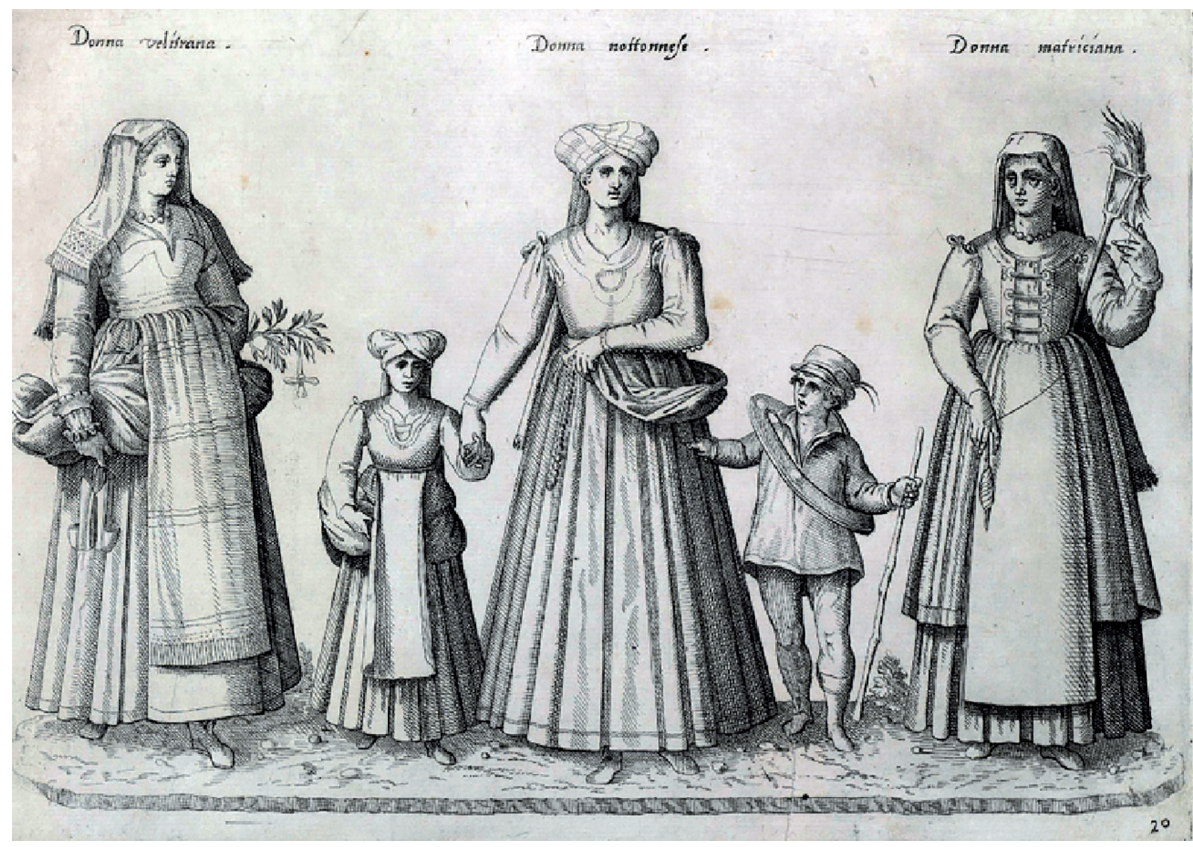

B. Grassi, De i veri ritratti degli'habiti di tutte le parti del mondo, 1585. BDH.

En tercer lugar, se conserva el Diversarum nationum habitus centum de Pietro Bertelli, una obra que edita en tres volúmenes en colaboración con Alciato Alciati, y cuyas partes salen en los años 1589, 1591 y 1596 respectivamente, desde su taller de Padua. A día de hoy, hay pocas bibliotecas que contengan los tres volúmenes completos de la obra ${ }^{45}$, sin embargo la Biblioteca Nacional de España, cuenta con una edición de cada uno, de los cuales, las tiradas de edición del primer y el segundo volumen son posteriores, por lo que no son correlativos. Físicamente, son libros muy

45. F. Borroni (1967). 
pequeños, como una edición de tipo viaje y las calcografías, contienen una imagen por cada, a veces acompañada de un fondo sencillo. Destaca sobre todo el interés por la representación de las gentes del Imperio turco.

\section{Imagen 3}

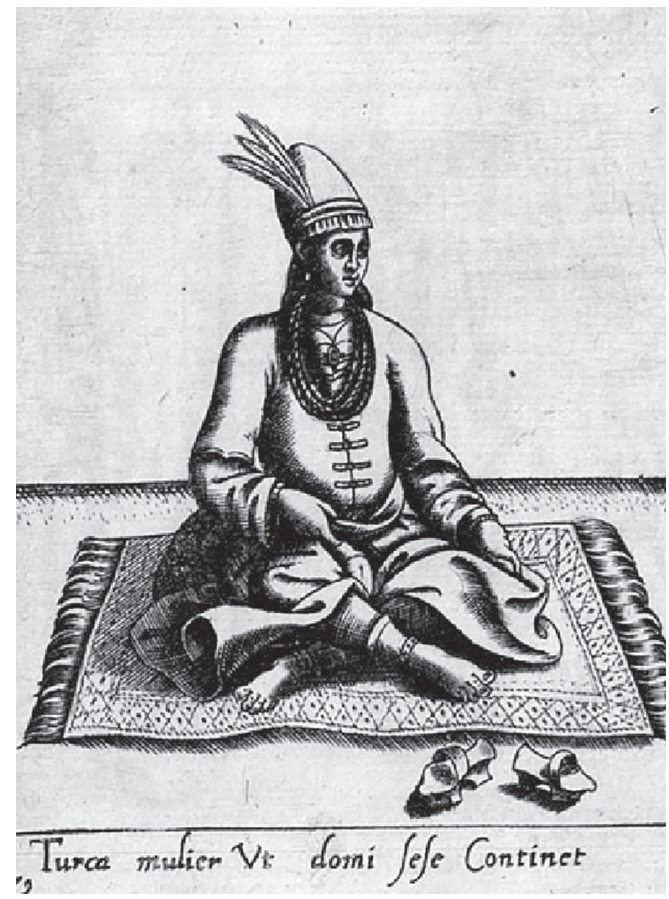

P. Bertelli, Diversarum nationum habitus centum,1591. BDH.

En cuarto lugar, contamos con tres ejemplares de la segunda edición del libro de trajes de Cesare Vecellio, el trabajo más ambicioso que se ha encontrado hasta el momento, Habiti antichi et moderni di tutto el mondo di Cesare Vecellio di nuovo acresciuti di molte figure, editado en Venecia en 1598. Una obra que, dada la cantidad de ejemplares y los estudios llevados a cabo sobre ella, suscitó y suscita gran interés. En especial, porque las xilografías de este libro de trajes se acompañan por un texto más o menos largo, que no solo se concentra en el vestido o sus materiales, sino en las formas del ser de las personas que aparecen en las distintas estampas. El proyecto de Cesar Vecellio pretendía abarcar con sus grabados, una recogida de información sobre todo el mundo conocido hasta el momento, introduciendo en esta edición de 1598, un considerable número de estampas sobre 
el continente americano, copiadas en parte de la obra de Bertelli y de los grabados de Theodore Bry y John White ${ }^{46}$.

Imagen 4

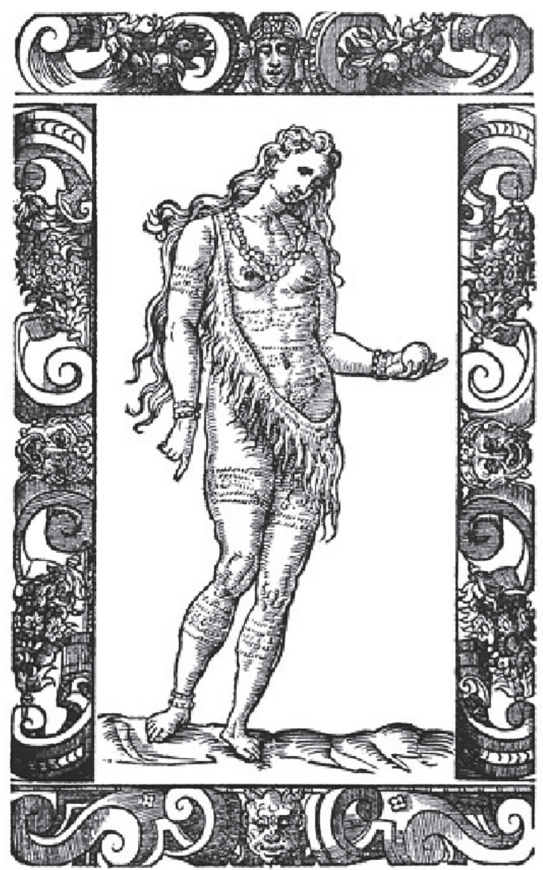

C. Vecellio, Habiti antichi et moderni di tutto el mondo di Cesare Vecellio di nuovo acresciuti di molte figure, 1598, y The clothing of the Renaissance world, 2008.

Por último, encontramos en la Biblioteca Nacional uno de los libros de trajes del grabador veneciano Giacomo Franco, Habiti delle donne venetiane intagliate in rame, editado en Venecia, con fecha de 1614. La obra, con un número de estampas considerablemente menor no solo que las de Vecellio, sino con el resto de autores, sigue sin embargo la estructura de estampa y texto, pero en su caso el grabado es calcográfico, que será el gran protagonista a partir del siglo XVII ${ }^{47}$. Tanto la calidad de las imágenes como la calidad en la elaboración del texto muestran el salto cualitativo que se produce entre una y otra centuria.

46. J. Guérin Dalle Mese (1998), 27-51.

47. A. Moreno Garrido (1979), 346. 


\section{Imagen 5}

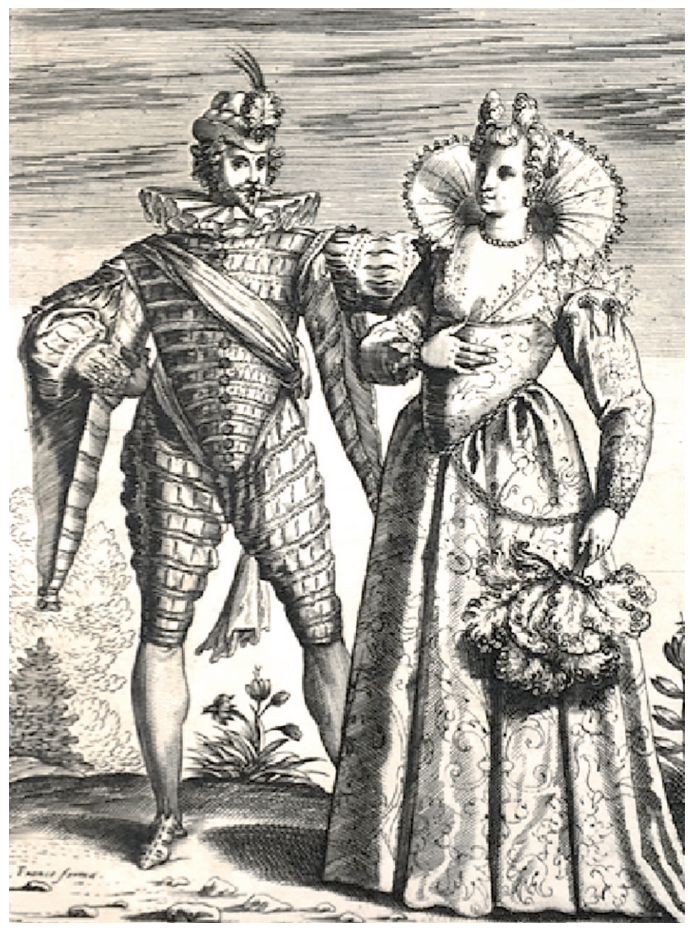

G. Franco, Habiti delle donne venetiane intagliate in rame, 1614. Biblioteca Nacional de España.

\section{UNAS PUNTUALIZACIONES FINALES SOBRE EL LIBRO DE TRAJES Y SU ESTUDIO DESDE UN POSICIONAMIENTO CRÍTICO}

Expuesto todo lo anterior, entendemos que resulta del máximo interés el estudio del libro de trajes desde una perspectiva multidisciplinar, abordado desde los estudios culturales y haciendo uso de la teoría feminista y poscolonial, ya que tanto la variedad de disciplinas, como las categorías que nos ofrece dicho marco teórico, nos permiten cuestionarnos, hacernos preguntas, observar minuciosamente la construcción de la(s) identidad(es) con respecto a la relación entre cuerpo(s), espacio(s), y poder y las barreras que se establecen en torno a los mismos.

Y en relación con lo dicho, uno de los primeros espacios a abordar es el propio libro de trajes, como plataforma de poder, difusión del conocimiento, y de una genealogía concreta del saber. Pues como lugar material, 
nos habla de otras áreas, como son la imprenta y sus estrategias de promoción, el mercado del libro, y lo que es mas importante, de los espacios de pensamiento y creación científica de los discursos dominantes. Por otro lado, observado desde su particularidad en el presente, el libro de trajes puede ser entendido como un archivo que encierra todas estas estrategias que encierran unos saberes y una forma de conocer el mundo específicos, y que se ha presentado como la cultura principal, tapando otras formas del ser y del conocer.

Ello nos lleva a su situación en el lugar físico, al fondo antiguo de las bibliotecas, desde donde se construye la propia memoria histórica, social y cultural, lugar en el que hallamos el reflejo de las estrategias del conocimiento del ayer, que deben ser críticamente abordadas desde el presente. Ejemplo de esto es, tal y como hemos visto, el fondo antiguo de la Biblioteca Nacional de España, que ilustra la importante difusión del libro de trajes como fuente visual/textual que participa de las redes del saber del Renacimiento científico, y que en la actualidad supone un verdadero reflejo del mismo.

Por todo, podemos afirmar que los libros de trajes suponen un modelo que nos sitúa ante una producción muy específica, en torno a una narrativa visual, de obras que como otras similares del siglo XVI, se colocan como eje vertebrador de la cultura científica. Un discurso que se presenta como universal y homogéneo debido a la centralización del mismo en la conceptualización de la idea de Europa, que pretende ser el lugar de partida del conocimiento hacia todo lo que se entiende como su propia otredad. Cuestiones que pueden ser puestas en tela de juicio gracias a posicionamientos críticos como los de Donna Haraway y su puntualización sobre la importancia del conocimiento situado, que rompe con una visión totalizadora de las normas y conceptos que configuran las distintas formas de expresión cultural ${ }^{48}$. Sumado a la crítica de autores que, como Enrique Dusse $^{49}$, inciden en el propio concepto de "exterioridad" europea, como todo aquello que constituye Europa para mostrar las formas del ser o del conocer ajenas a su discurso, y que van a ser determinadas como contranormativas o subexcéntricas. Una visión que justificará acciones políticas como las guerras en el Mediterráneo o la colonización del Atlántico y el Pacífico.

Cartografías corporales que por tanto, se presentan como una verdadera genealogía de saber, de representación, en torno a unas ideas que se repiten y articulan de manera jerárquica partiendo de la diferencia como indicador

48. D. Haraway (1988).

49. E. Dussel (2000), 28-29. 
principal. Una diferencia que permite un análisis profundizado del cuerpo en su construcción desde parámetros eurocéntricos, heteronormativos y patriarcales, que pueden ser interpelados desde conceptos analíticos como el género, el estatus y la raza.

Textos visuales que nos sitúan y hablan del propio contexto, que disponen algunas de las estrategias a través de las cuales se erige la identidad europea del quinientos, y que, a su vez, han sido indisolublemente ligadas a la conceptualización del propio presente, gracias a la permanencia y salvaguarda de estas fuentes en los grandes centros dominantes del conocimiento: las bibliotecas.

\section{BIBLIOGRAFÍA}

Amman, Jost (1577), Habitus praecipuorum populorum, Hans Weigel, Nürnberg. BALlerus, Joanes (1572), Omnium fere gentium, nostraeque aetatis nationum habitus et effigies, Amberes.

Anómino Ioanni Bellero excudebat (Aegidius Radaeus), Antverpiae.

Barker, Chris \& JAne, Emma A. (2016), Cultural Studies: theory and practice, SAGE Publications, Los Angeles.

Bertelli, Ferdinando (1563), Omnium fere gentium nostrae aetatis habitus, Ferdinando Bertelli, Venetiis (Venecia), 1. ${ }^{\text {a }}$ ed. Segunda edición: 1569.

Bertelli, Pietro (1589-1591-1596), Diversarum nationum habitus centum, 3 vols., Padua.

apud Alciatum Alcia et Petrum Bertellium, Patavii (Padua), 1594.

Bнавна, Homi K. (2002), El lugar de la cultura, Ediciones Manantial, Buenos Aires.

Birriel Salcedo, Margarita M. (2013), "Clasificando el mundo: Los libros de trajes en la Europa del siglo XVI”, en M. García Fernández (dir.), Cultura material y vida cotidiana moderna: escenarios, Sílex, Madrid, pp. 261-278.

- (2016), "Espacio y género en la Edad Moderna. Retos, problemas y logros de la investigación”, en C. Martínez López, Á. Muñoz-Fernández, M. M. Birriel Salcedo, J. Luengo López y C. Campos Luque, Mujeres e historia, Universidad, Valladolid, pp. 89-120.

- (2019), "Las moriscas del reino de Granada. Repensando el conflicto étnico religioso desde el género", en C. MARTínez Shaw (coord.), Una vida dedicada a la Universidad. Estudios en homenaje al profesor José Manuel de Bernardo Ares, Universidad, Córdoba, pp. 151-170.

Boisard, Jean Jacques (1581), Habitus variarum orbis gentium, [Caspar Rutz], [s. 1.] Paris.

Borroni, Fabia (1967), "Bertelli, Pietro", en Dizionario Biografico degli Italiani, Istituto dell'Enciclopedia Italiana Treccani. URL: <https://www.treccani. it/enciclopedia/pietro-bertelli_\%28Dizionario-Biografico\%29/> (última consulta: 7/10/2019). 
Brown, Alison (1999), The Renaissance, Routledge, New York.

BRÜYn, Abraham (1581), Omnium pene Europae, Asiae, Aphricae, atque Americae gentium habitus, Amberes. Abraham de Bruijn excudit, [Amberes?].

Burke, Peter (2000), El Renacimiento europeo. Centros y periferias, Crítica, Barcelona.

- (2001), El Renacimiento italiano. Cultura y sociedad en Italia, Alianza Forma, Madrid.

- (2005), Visto y no visto. El uso de la imagen como documento histórico, Crítica, Barcelona.

Butler, Judith (2002), Cuerpos que importan. Sobre los limites materiales y discursivos del "sexo", Paidós, Buenos Aires.

Cavarero, Adriana (2011), Tu che mi guardi, tu che mi racconti. Filosofia della narrazione, Feltrinelli, Milano.

Chartier, Roger (2000a), Entre poder y placer. Cultura escrita y literatura en la Edad Moderna, Cátedra, Madrid.

- (2000b), Cultura escrita, literatura e historia, Fondo de Cultura Económica, México.

Cixous, Hélène (1995), La risa de la medusa. Ensayos sobre la escritura, Anthropos, Barcelona.

Defert, Daniel (1984), “Un genre ethnographique profane au XVIe: les livres d'Habits", en R. Rupp-Eisenreich (comp.), Histoires de l'Antropologie (XVIe-XIXe siècles), Klincksieck, Paris.

Dussel, Enrique (2000), "Europa, modernidad y eurocentrismo", en E. LANDER (comp.), La colonialidad del saber: eurocentrismo y ciencias sociales. Perspectivas latinoamericanas, CLACSO, Buenos Aires, pp. 24-33.

FArge, Arlette (2004), Allure of the Archives, Yale University Press, New Haven. Foucault, Michel (1979), La arqueología del saber, Siglo Veintiuno, México.

Franco, Giacomo (1614), Habiti delle donne venetiane intagliate in rame, Venecia.

GARCÍA HARO, Rebeca (2018), Cuerpos que cuentan y cuerpos que son contados. Género, alteridad y representación en los libros de trajes durante el Renacimiento, Universidad de Granada y Universidad de Bolonia, Granada. Trabajo final de máster.

Gilroy, Paul (2014), Atlántico negro. Modernidad y doble conciencia, Akal, Madrid. Grassi, Bartolomeo (1585), De i veri ritratti degli'habiti di tutte le parti del mondo. Intagliati in rame per opra di Bartolomeo Grassi, [s. n.], Roma.

Guérin Dalle Mese, Jeannine (1998), L'occhio di Cesare Vecellio. Abiti e Costumi Esotici nel '500, Edizioni dell'Orso, Torino.

Haraway, Donna (1988), "Situated Knowledges: The Science Question in Feminism and the Privilege of Partial Perspective", Feminists Studies, 14, 3, pp. 575-599.

- (2016), A Cyborg Manifesto. Science, Technology and Socialist-Feminism in Late Twentieth Century, University of Minnesota Press, Minneapolis. 
ILG, Ulrike (2004), "The cultural Significance of Costume Books in SixteenthCentury Europe", en C. Richardson (ed.), Clothing Culture, 1350-1650, Routledge, pp. 29-47.

Jones, Amelia (2003), The Feminism and the Visual Culture Reader, Routledge, London.

Márquez Estrada, José Wilson (2014), "Michel Foucault y la Contra-Historia", Historia y Memoria, 8, pp. 211-243.

McDowell, Linda (2000), Género, identidad y lugar. Un estudio de las geografías feministas, Cátedra, Madrid.

Mignolo, Walter (2007), "El pensamiento decolonial: desprendimiento y apertura. Un manifiesto", en S. Castro-Gómez y R. Grosfoguel (eds.), El giro decolonial. Reflexiones para una diversidad epistémica más allá del capitalismo global, Siglo del Hombre Editores, Bogotá, pp. 25-46.

Moreno Garrido, Antonio (1979), “Algunas consideraciones en torno al estudio del grabado español del siglo XVII”, Mayurqa, 19, 1, pp. 337-352.

Paulicelli, Eugenia (2016), Writing Fashion in Early Modern Italy. From Sprezzatura to Satire, Routledge, New York.

Pettegree, Andrew (2010), The Book in the Renaissance, Yale University Press, New Haven.

QuiJano, Aníbal (2007), "Colonialidad del poder y clasificación social”, en S. Castro-Gómez y R. Grosfoguel (eds.), El giro decolonial. Reflexiones para una diversidad epistémica más allá del capitalismo global, Siglo del Hombre Editores, Bogotá, pp. 93-126.

Rosenthal, Margaret F. \& Jones, Ann Rosalind (2008), The Clothing of the Renaissance World. Europe, Asia, Africa, Americas, Thames \& Hudson, London.

Rose, Gillian (2001), Visual Methodologies. An Introduction to the Interpretation of Visual Materials, SAGE Publications, London.

Rublack, Ulinka (2010), Dressing Up. Cultural Identity in Renaissance Europe, Oxford University Press, New York.

Ruíz Álvarez, Raúl (2011), Andalucía y sus gentes en el Civitates Orbis Terrarum (1572-1617), Universidad, Granada. Trabajo final de máster.

- (2013), Mirar al morisco. Planteamientos propuestas y reflexiones sobre el imaginario morisco en la Edad Moderna, Universidad Internacional de Andalucía y Universidad Pablo de Olavide, Sevilla. Trabajo final de máster.

SAID, Edward (2008), Orientalismo, Debolsillo, Barcelona.

SPIVAK, Gayatri Chakravorty (1998), ¿Puede hablar el sujeto subalterno?”, Orbis Tertius, 6, pp. 175-235.

Sturken, Marita \& Cartwright, Lisa, (2009), Practices of Looking. An Introduction to Visual Culture, Oxford University Press, New York.

TILLEY, Christopher (2006), Handbook of Material Culture, SAGE Publications, London.

Vecellio, Cesare (1598), Habiti antichi et moderni di tutto il mondo di Cesare Vecellio di nuovo acresciuti di molte figure, appresso Gio. Bernardo Sessa, Venetia, 2. ${ }^{\mathrm{a}}$ ed. 
- (2008), The Clothing of the Renaissance World, Thames \& Hudson. Eds.:

Margaret F. Rosenthal \& Ann Rosalind Jones, New York.

Wiesner-Hanks, Merry E., (2013), Early Modern Europe (1450 - 1789), Cambridge

University Press, Cambridge. 